Fecha de recepción: diciembre 2017

Fecha de aceptación: marzo 2018

Versión final: julio 2019

\section{La imagen vigilante: acerca de la fotografía policial como instrumento del poder}

María Elsa Bettendorff *

Resumen: Incorporadas al dispositivo de vigilancia del Aparato Represivo de Estado, el carácter de prueba o evidencia de las fotografías de los archivos policiales es producto de una construcción institucional que convierte en saber aquello que inicialmente se percibe como huella de un acontecer. En este artículo nos dedicamos, precisamente, a examinar la funcionalidad de este género de imágenes al interior de la Dirección de Inteligencia de la Policía de la Provincia de Buenos -DIPBA- en el periodo 1962-1973. Proponemos además el concepto de "memoria escópica" para dar cuenta del modo de ver/mostrar/saber propio de la institución en relación con su producción fotográfica.

Palabras clave: archivo - comunidad discursiva - fotografía policial - géneros fotográficos - memoria - poder.

[Resúmenes en inglés y portugués en la página 122]

${ }^{(*)}$ Licenciada en Letras (Facultad de Filosofía y Letras de la Universidad de Buenos Aires), con formación de posgrado en Análisis del Discurso, Lingüística Textual (F.F.y L., U.B.A.) y Docencia Universitaria (Rectorado de la Universidad de Buenos Aires). Especializada en Estudios Visuales. Actualmente se desempeña como profesora adjunta de la cátedra Vitale de Semiología (Ciclo Básico Común de la Universidad de Buenos Aires) y profesora titular de Discurso Audiovisual, Teorías de la Comunicación y Metodología de la Investigación en la Facultad de Diseño y Comunicación de la Universidad de Palermo. Participa en proyectos de investigación (UBACyT; PICT) sobre los archivos de la represión.

\title{
Observaciones preliminares
}

Como ha advertido Georges Didi-Huberman (2013), una de las grandes fuerzas de la imagen es la de crear, al mismo tiempo, síntoma y conocimiento. Las fotografías de los archivos policiales se encuentran, tal vez, dentro de las manifestaciones más acabadas de ese doble poder de las imágenes: incorporadas al dispositivo de vigilancia del Aparato Represivo de Estado, su carácter de prueba o evidencia es producto de una construcción institucional que convierte en "saber" aquello que inicialmente se percibe como huella de 
"algo que ha ocurrido". En este trabajo, resultado de un continuo proceso de análisis de la documentación visual incorporada a los expedientes confeccionados por la Dirección de Inteligencia de la Policía de la Provincia de Buenos Aires -DIPBA- (desarrollado a lo largo de nuestra participación en sucesivos proyectos de investigación centrados en su Archivo $^{1}$ ), nos dedicamos precisamente a reconstruir ese pasaje (que, desde un punto de vista retórico, no es otro que el de la selección del dato a la instauración de su sentido -Perelman y Olbrechts-Tyteca, 1989-) en relación con las prácticas de dicho organismo como comunidad discursiva ${ }^{2}$.

Sobre la base de un corpus documental constituido por legajos ${ }^{3}$ elaborados por la institución entre 1962 y 1973 (es decir, desde la coyuntura histórico-política de la proscripción del peronismo hasta el retorno de Juan Domingo Perón a la Argentina), examinamos aquí la funcionalidad de la fotografía policial ${ }^{4}$ como género que contribuye a la especificidad de la producción discursiva del grupo investigado y a la constitución de su memoria como comunidad, en conexión con los textos dedicados al suministro de información. El carácter interdisciplinario de nuestro abordaje se pone de manifiesto en la incorporación de un repertorio conceptual y una orientación metodológica procedentes, por un lado, del análisis del discurso y, por otro, de la semiótica de la imagen y el campo de los estudios visuales. Presentamos, a continuación, los fundamentos teóricos de dicho abordaje, para dar cuenta luego de los resultados de nuestra indagación.

\section{Hacia una conceptualización semiótico-discursiva de la fotografía policial de los archivos de inteligencia}

Para empezar, adoptamos como definición de "imagen de archivo" (en la que queda comprendido nuestro objeto de estudio) la ofrecida (desde la teoría y crítica de las culturas visuales) por el investigador británico John Tagg (2005), quien la caracteriza como:

[...] una imagen producida de acuerdo con determinadas normas formales y procedimientos técnicos de carácter institucionalizado que definen cuáles son las manipulaciones legítimas y las distorsiones permisibles, de modo que, en ciertos contextos, unos intérpretes más o menos hábiles y adecuadamente formados y autorizados pueden extraer conclusiones de ella, sobre la base de convenciones históricamente establecidas. Es únicamente en este marco institucional donde adquieren peso y pueden imponerse significados que de otro modo podrían ser discutibles (p. 8$)^{5}$.

Esta descripción tiene la ventaja de conducirnos inmediatamente a la consideración de la fotografía de archivo policial como emergente de la actividad propia de la institución que la genera y conserva, entendida esta última como comunidad discursiva: el uso de la imagen fotográfica como indicio, vestigio, prueba y/o evidencia es parte del proceso de "producción de información" de la inteligencia policial, práctica que define al grupo; dentro de este proceso, la fotografía se concibe como tecnología que aporta "objetividad" y rigor documental a la tarea investigativa. En este sentido, es un producto material inscrip- 
to en el sistema semiótico-discursivo de la comunidad, cuyo valor representativo surge de fines específicos en un contexto también específico (que le concede su "poder de verdad"). Como también observa Tagg:

Según la moderna economía fotográfica, la foto como medio carece de significado fuera de sus especificaciones históricas. Lo que le da sentido e identidad, su naturaleza como práctica, depende de las instituciones y los agentes que la definen y la ponen en funcionamiento. Es significativa y legible sólo dentro de usos específicos. Nunca es neutral (al igual que el estado). Las representaciones que produce están sumamente codificadas y el poder que ejerce nunca es su propio poder (ibíd., p. 85).

Cabe recordar que, en cuanto género visual documental, la fotografía policial (desde su irrupción en el siglo XIX) suele asociarse a finalidades "científicas" que acompañan la progresiva profesionalización de las fuerzas del orden (Montiel Álvarez, 2016), tanto en su empleo en criminalística (en especial, como herramienta de la inspección ocular técnicopolicial en el lugar de un hecho ya acaecido) como en su utilización como medio de vigilancia y control social (aspecto que guarda correspondencia con las funciones de la DIPBA y que subrayamos en este artículo). Justamente, esa "cualidad genérica" concuerda con la concepción de la Inteligencia como una disciplina científica que, junto al ethos o imagen de sí que los agentes construyeron en sus discursos (experticia, pretensión de objetividad, claridad, lenguaje "transparente", monologismo), atraviesa la memoria discursiva de la comunidad investigada (Vitale, 2016).

Avancemos ahora hacia la dimensión enunciativa de la producción fotográfica policial. Como se sabe, desde un enfoque discursivo (incluso aislada de su anclaje verbal), la imagen puede ser tratada como un enunciado. Al respecto, ha observado Gauthier (1996):

Como enunciado, la imagen tiene una estructura, homóloga o no, de un conjunto directamente percibido (los objetos, su disposición respecto del observador, su exposición a las fuentes de iluminación), siempre en relación con un espacio autónomo bidimensional, generalmente en un cuadrado o rectángulo (...). Comparándolo con un enunciado lingüístico, ¿qué podemos decir de este enunciado icónico? En los términos expuestos por J. L. Austin, vemos que la imagen puede ser considerada como un "enunciado constatativo", cuya función puede ser describir hechos o estados de cosas (pp. 232-233).

Este carácter constatativo del enunciado visual se reforzaría en el caso de la imagen fotográfica, como antes había advertido Barthes (1980), para quien la cámara es, precisamente, un instrumento de constatación, ya que establece una conexión material entre la "cosa" necesariamente real colocada ante el objetivo y la imagen obtenida, lo que remite a su naturaleza indicial (Schaeffer, 1990). Sin embargo, como recién hemos visto, ese poder es verdaderamente ejercido por la fotografía sólo dentro de ciertas prácticas institucionales y relaciones históricas concretas. En el marco del organismo de inteligencia, no sólo se inviste de esa fuerza constatativa (refrendada por la exigencia de cientificidad) sino que ad- 
quiere también (recurriendo a otro concepto perteneciente a la teoría de Austin -1981-) un carácter performativo: el acto fotográfico, que sitúa al enunciador-fotógrafo en una suerte de "futuro anterior" (Chevrier, 1982) en la medida en que cristaliza un espacio y un instante destinados a una contemplación posterior (es decir, se inscribe en un presente que es experimentado como "el pasado de un futuro"), no es aquí el mero registro de un acontecer, sino el resorte de otro actuar que a su vez lo autoriza; en efecto, como operación de espionaje o vigilancia, se enlaza a una secuencia de acciones dirigidas a la construcción de un "saber" experto que prescribe un "hacer" sobre los objetos-sujetos observados. En otras palabras: como enunciados visuales, las fotografías tomadas por los agentes de inteligencia no se limitan a confirmar "objetivamente" estados de cosas o hechos acaecidos, sino que (como las expresiones realizativas) tienen la propiedad de cumplir un acto (en este caso, el de vigilar) con determinados efectos (como el de convertir en "vigilados" a los individuos fotografiados) en el mismo momento de su enunciación, bajo ciertas condiciones y requisitos.

\section{De la vigilancia fotográfica a la "memoria escópica"}

De las consideraciones anteriores deriva nuestra principal hipótesis de investigación: en su estatus de enunciados visuales, las fotografías producidas por los organismos de inteligencia no son unidades portadoras de significado en sí mismas, sino componentes de una serie históricamente situada que responde a la distribución de funciones dentro de una práctica discursiva institucional, práctica en la que se va construyendo una cierta memoria en relación con saberes y haceres compartidos por la comunidad. Es en el dominio del archivo (no sólo como dispositivo de ordenamiento y conservación documental, sino fundamentalmente -adaptando la concepción de Foucault, 2002- como sistema que regula la misma aparición de lo "informable" o comunicable al interior de esa comunidad) donde se sedimenta un cierto modo de ver/mostrar los sujetos, objetos y espacios vigilados, modo que se somete, tal como venimos subrayando, a los imperativos de cientificidad (y también de performatividad) propios de la producción de inteligencia. Nos referimos a lo que autores como Jay (2003) han llamado "régimen escópico": un paradigma de visualidad que regiría, con pocas alteraciones a lo largo del tiempo, tanto las operaciones de registro fotográfico de los agentes involucrados en esa tarea como la estimación (selección, clasificación, interpretación como dato) de las imágenes por parte de otros integrantes del organismo. En trabajos anteriores (Bettendorff, 2017; Bettendorff y Ledesma, 2018) hemos señalado que dicho régimen (al menos en el caso de la fotografía policial del archivo de la DIPBA fechada dentro del periodo estudiado) oscila entre los dos modelos canónicos de la modernidad reconocidos por el autor mencionado ${ }^{6}$ : por un lado, se ajusta a la vocación empirista del arte de describir, con su "ojo atento a la superficie fragmentada, detallada y ricamente articulada de un mundo que se contenta con describir grado a grado, antes que explicar en su conjunto" (Alpers, como se cita en Jay, p. 232); por otro, recoge la impronta racionalista del perspectivismo cartesiano, ya que las intervenciones efectuadas sobre las imágenes obtenidas (como veremos inmediatamente) obedecen a las exigencias de claridad y experticia explicitadas en la consideración "cientí- 
fica" de la información, en función de sus finalidades de control. Como observamos en el apartado precedente, el énfasis en estos últimos rasgos es parte de la memoria discursiva de la institución policial; de esta manera, se hace posible introducir la noción de "memoria escópica" (en la intersección de los dos territorios epistémicos en los que nos ubicamos para abordar nuestro objeto de estudio: el análisis del discurso y los estudios visuales), que definimos provisoriamente como la reiteración o el reacomodamiento de una determinada "mirada institucional" en las producciones visuales de una comunidad discursiva en distintas coyunturas históricas, para dar cuenta de las regularidades y variaciones de ese modo de ver/mostrar lo vigilado dentro del organismo.

\section{Tres momentos, una mirada}

Pasamos ahora a reseñar los resultados de nuestro análisis, tomando como ejemplo tres conjuntos de fotografías ${ }^{7}$ incorporados a legajos confeccionados por la DIPBA en diferentes circunstancias histórico-políticas.

El primer conjunto, incluido en una unidad documental referida al sindicato de la carne de Berisso (Mesa B -información sobre actividad sindical y fabril-, carpeta 16, legajo $\mathrm{N}^{\circ}$ 1) y elaborada entre 1960 y 1962, está conformado por dos series de fotos (la primera de sesenta y cinco imágenes y la segunda de once), separadas por distintas carátulas pero fechadas ambas el 7 de septiembre de 1962. Las dos series registran escenas de un acto público convocado por las organizaciones sindicales de Swift y Armour en las calles Guayaquil y Montevideo de Berisso, en el contexto de la larga huelga de los trabajadores de los frigoríficos iniciada en agosto de ese año ${ }^{8}$. Dentro de la documentación escrita del legajo, el único texto que remite al hecho fotografiado es un memorándum ${ }^{9}$ del mes anterior (29/8/62), en el que se comunica a la superioridad la postergación del acto:

Llevo a conocimiento del Sr. Jefe que en la fecha, comunica la U. Regional LA PLATA, que el acto programado en la localidad de BERISSO para el día de mañana a las 17 horas por el personal que agrupa el gremio de la carne, en las calles Guayaquil y Montevideo, ha sido diferido para el día 6 del mes próximo a la misma hora. Ello obedece a la concordancia existente en día y hora, con la realización de una mesa redonda que se llevará a cabo en el local central de la C.G.T., en la Capital Federal (S.I.P.B.A. ${ }^{10}$, Archivo y Fichero, Mesa B, carpeta 16 , legajo 1 , folio 63 ).

La modificación ulterior de la fecha queda salvada en las portadas que rotulan las series fotográficas. La información contenida en el memorándum no tiene otro propósito que el de advertir sobre la necesidad de reajustes en las actividades de seguimiento de los huelguistas por parte de la fuerza policial. Será la fotografía la que, en este caso, concrete la acción sugerida.

Al revisar los subconjuntos, se hace evidente que el último (folios 56 a 62) es fruto de una selección y posterior intervención sobre el anterior (folios 31 a 55): las once imágenes que conserva han sido, en varios casos, recortadas y ampliadas para facilitar la identifi- 
cación de los participantes del acto. El "ojo del poder" ha descartado la insignificancia de unos momentos, de unos espacios, de unos cuerpos. En la primera serie, el acto ha sido interrumpido por la lluvia y los asistentes se dispersan para buscar abrigo; allí, los signos literales (icónicos) se desdibujan entre los abstractos (fotogénicos: ópticos, lumínicos, cinéticos -Zunzunegui, 1995-), como se advierte en la Figura $\mathrm{N}^{\circ} 1$. En la segunda serie, la escena se omite. Precisamente donde el dispositivo fotográfico se revela como artefacto, la representación parece volverse disfuncional.

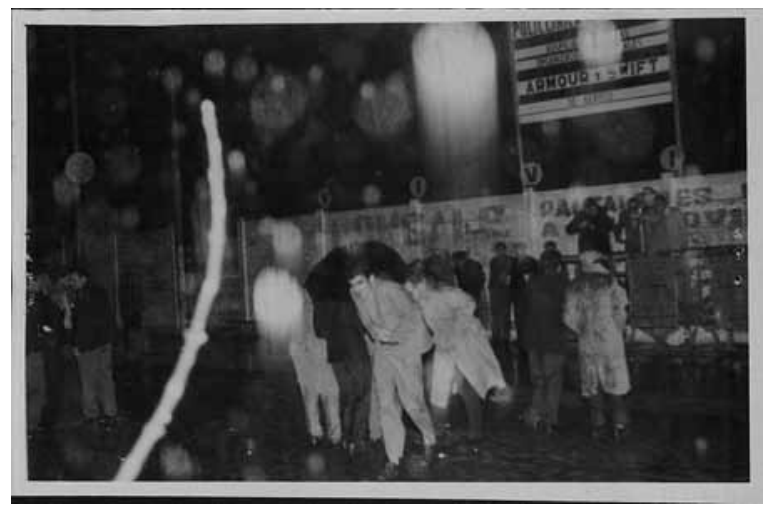

Figura $\mathrm{N}^{\circ}$ 1. (S.I.P.B.A., Archivo y Fichero, Mesa B, carpeta 16, legajo 1 , folio 36 -primera serie-)

En ambos casos, el orden de presentación de las imágenes es deliberado. La sintaxis, como procedimiento de connotación (Barthes, 1986), introduce una cronología mínima pero eficaz. En la fotografía aislada se impone la espacialidad propia de la descripción; el tiempo es así un dato implícito (ligado a su génesis, a su interpretación como huella de algo que ha sido). La secuencia, legible como relato, recrea el flujo de una temporalidad posible. Las dos series pueden entenderse, entonces, como dos crónicas sobre un mismo acontecimiento. La segunda es la que sintetiza escrupulosamente "lo que debe saberse" del acto sindical: la sucesión de oradores, la presencia de público, la elocuencia de los gestos.

Cada fotografía materializa, por supuesto, un punto de vista. El encuadre es su manifestación tanto formal como ideológica (Aumont, 1990). El espacio representado en la imagen es el que contiene la iconografía del activismo gremial: un estrado, el muro de un establecimiento, un cartel que fija una pertenencia ("Organizaciones sindicales Armour y Swift de Berisso"), un pequeño grupo de hombres firmes ante una audiencia inquieta. El fuera de campo es el terreno imaginario de lo que no merece atención. Como ya señalamos, el pasaje del primer al segundo subconjunto modifica leve pero incisivamente ese punto de vista originado en la mirada del fotógrafo. El campo se contrae, a la vez que la información se despliega: el contraste se acentúa, los rostros de los oradores cobran identidad y la vigilancia comienza a ejercer sus efectos, como lo demuestra el agregado de números manuscritos (ver Figuras $\mathrm{N}^{\circ} 2$ y No3). 

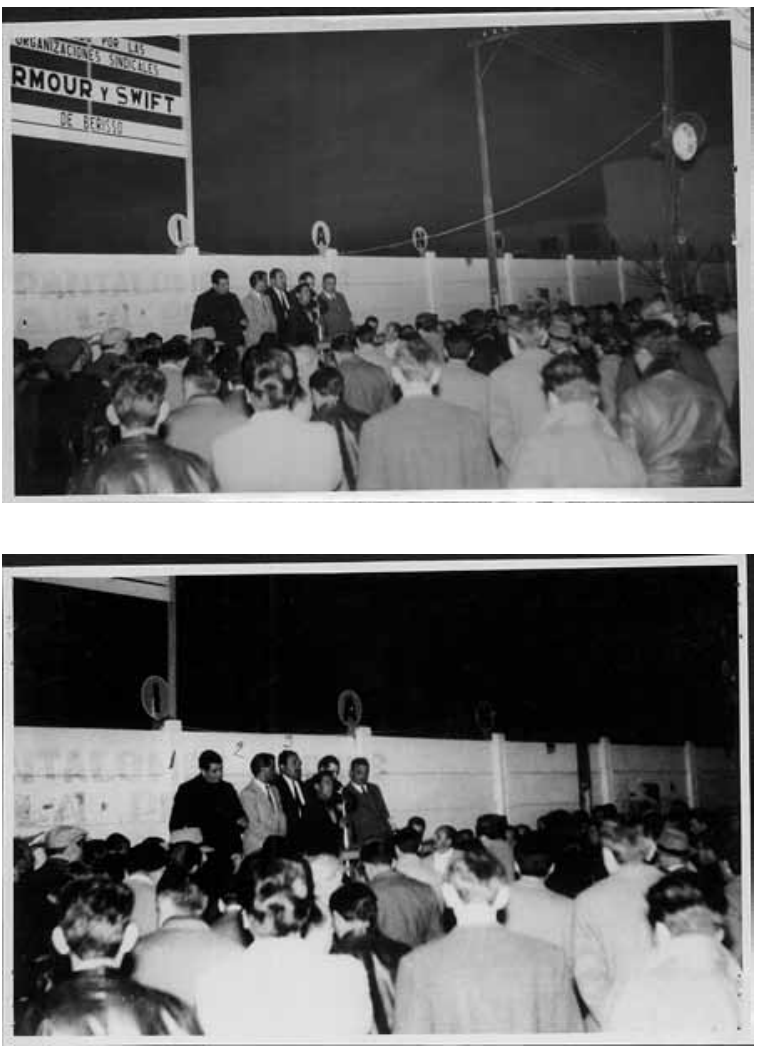

Figura $\mathrm{N}^{\circ} 2$ (arriba).

(Ibidem, folio 36

-primera serie-).

Figura $\mathrm{N}^{\circ} 3$ (abajo).

(Ibidem, folio 62

-segunda serie-).

El segundo conjunto de imágenes que ilustra nuestro análisis está integrado por diecinueve fotografías que acompañan un informe sobre la peregrinación a Luján de pobladores de distintas "villas miseria" de la Capital y el conurbano realizada el 28 de diciembre de 1969, que tuvo como organizadores a representantes del Movimiento de Sacerdotes para el Tercer Mundo ${ }^{11}$ (Mesa Referencia, legajo $\mathrm{N}^{\circ} 10141$, tomo 2). En este caso, el texto informativo (folio 201), fechado el mismo día, se reduce a datos "objetivos": cantidad de concurrentes, procedencia, secuencia y horarios de actividades, oradores. Es el material visual adjunto (mencionado en el informe) el que revela verdaderamente la "peligrosidad" de los vigilados: sus demandas, sus desplazamientos, su presencia disruptiva para el orden social que se intentaba preservar. Las fotografías (que no llevan epígrafes, sino que tienen como único anclaje el título general "Fotografías-Concurrentes y Oradores" que las precede) reproducen, fragmentariamente, el espacio y los protagonistas de las acciones enumeradas: planos generales y planos conjunto de los peregrinos frente a la basílica, portando letreros que indican su pertenencia, en diferentes angulaciones; planos medios (largos y cortos) 
de los oradores y sus asistentes, que facilitan su identificación; ninguna mirada a cámara: sólo instantes, posiciones y gestos espontáneos hurtados en el acto fotográfico (ver, como ejemplos, las Figuras $\mathrm{N}^{\circ} 4$ a $\mathrm{N}^{\circ} 7$ ).
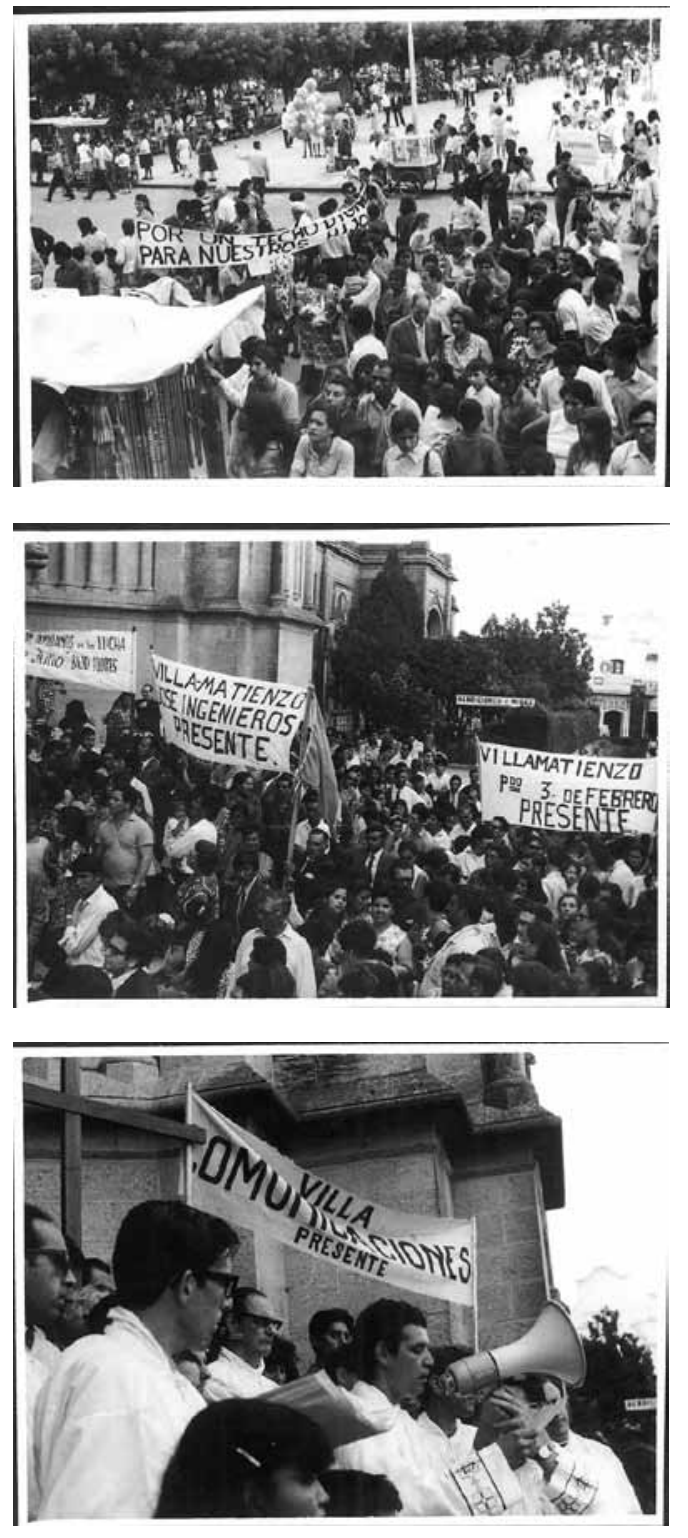

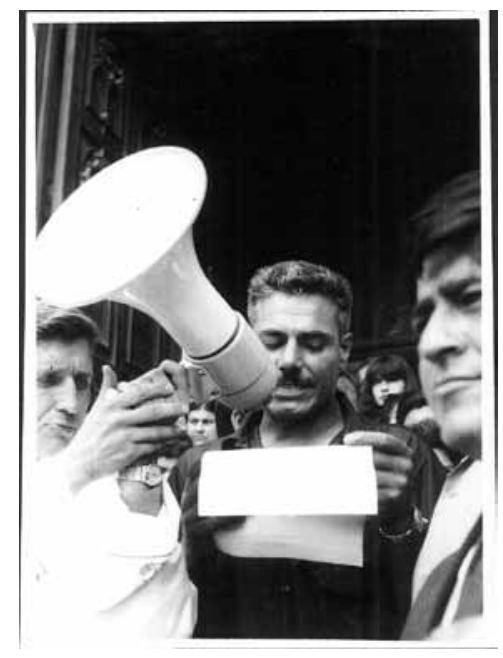

Figura $\mathrm{N}^{\circ} 4$ (arriba

izq.). (Mesa Referencia, legajo $\mathrm{N}^{\circ} 10141$, tomo 2 , material adjunto al informe del folio 201). Figura $\mathrm{N}^{\circ} 5$ (centro). (Ibidem).

Figura $\mathrm{N}^{\circ} 6$ (arriba der.).(Ibidem).

Figura $N^{\circ} 7$ (abajo). (Ibidem). 
Impacta, particularmente, la imagen-estereotipo de un "niño villero" (retratado en plano americano) que lleva en sus manos un cartel con la leyenda "Virgencita de Luján-Tu pueblo trabajador reclama tu protección". En los folios, esta foto aparece separada de la serie, como un retazo de pathos que debe disociarse de la eficiencia descriptiva de la secuencia (ver Figura $\mathrm{N}^{\circ} 8$ ).

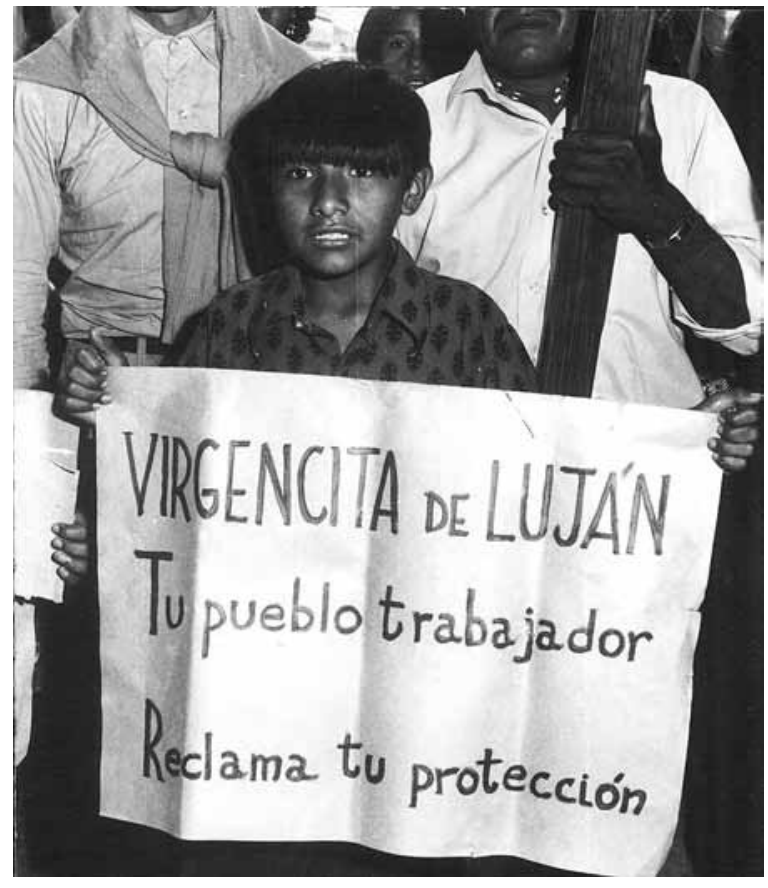

Figura No8. (Mesa

Referencia, legajo $\mathrm{N}^{\circ} 10141$, tomo 2, entre folios 207 y 208)

El último grupo de fotografías que seleccionamos para este trabajo se incluye en el legajo $\mathrm{N}^{\circ} 188$, tomo III, carpeta 37, de la Mesa A (actividad política), cuyo asunto (indicado en la carátula) es el "Movimiento Nacional Justicialista". El expediente, elaborado en 1973, contiene un extenso informe relativo a una movilización organizada en julio de ese año por la Juventud Peronista hacia la residencia de la calle Gaspar Campos (en la localidad de Vicente López) en la que se domicilió Juan Domingo Perón tras su retorno al país ${ }^{12}$. Dicho informe se encabeza con un índice de contenidos, cuyo último punto anticipa el registro fotográfico del evento ("Fotografías del acto"). En los folios dedicados a la "Actitud que le cupo al personal del S.I.P.B.A." ${ }^{13}$ se reseña la participación del organismo en el operativo de seguridad montado por las fuerzas policiales para prevenir acciones de grupos armados 


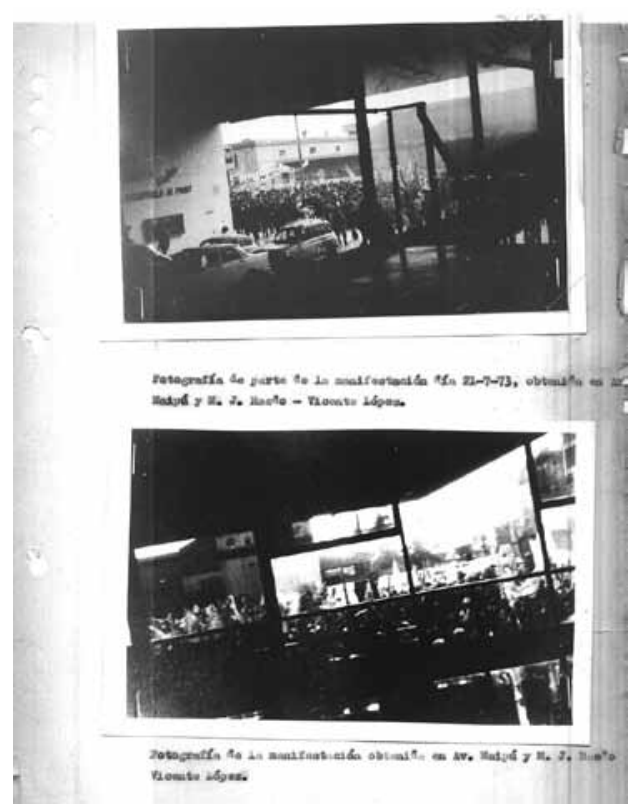

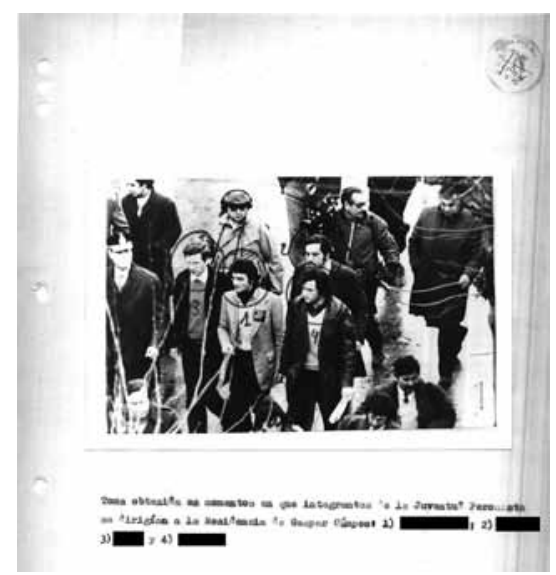

Figura $\mathrm{N}^{\circ} \mathbf{9}$ (izq). (Mesa

A, legajo $\mathrm{N}^{\circ} 188$, tomo III, carpeta 37, folio 186)

Figura $\mathrm{N}^{\circ} 10$ (arriba).

(Ibidem, folio 188)

y se explicita que "se contó con equipo técnico fotográfico de las delegaciones de San Martín y Tigre [...], habiéndose obtenido algunas tomas fotográficas que se adjuntan" (folio 152 del legajo). Se trata de dieciséis fotografías que, al igual que en los casos anteriores, exponen fragmentariamente distintas escenas del suceso: por un lado, imágenes de la concentración en la Avenida Maipú, obtenidas desde el interior de un edificio; por otro, tomas de los representantes de la JP dirigiéndose a Gaspar Campos (en algunos casos, intervenidas con círculos y números manuscritos que remiten a su identificación) escoltados por policías y de otros asistentes a la movilización (algunas reencuadradas para facilitar el reconocimiento); finalmente, registros de la presencia de camarógrafos y del operativo de seguridad. Todas las fotos (en su mayor parte acompañadas por epígrafes que funcionan como anclaje verbal en el plano denotativo, lo que diferencia a este conjunto de los ya analizados ${ }^{14}$ ) revelan el punto de vista del enunciador-fotógrafo como observador no participante, distanciado de la escena registrada para ocultar su acción e instalado en una ubicación estratégica (como se advierte en las angulaciones oblicuas y picadas). El título "Diferentes tomas fotográficas" en varios de los folios donde figuran las imágenes absorbe las visiones particulares de los anónimos agentes en una única mirada: la del enunciador institucional (ver Figuras $\mathrm{N}^{\circ} 9$ a $\mathrm{N}^{\circ} 14$ ). 

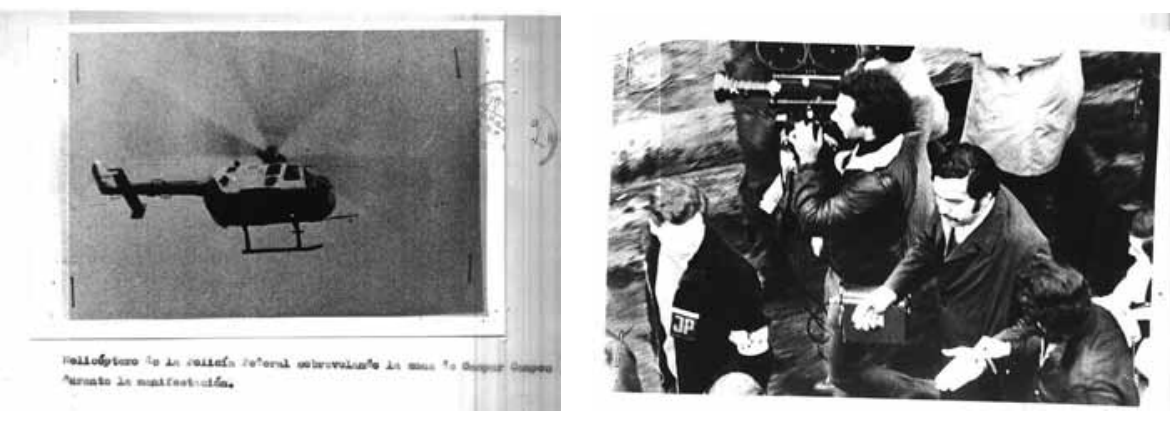

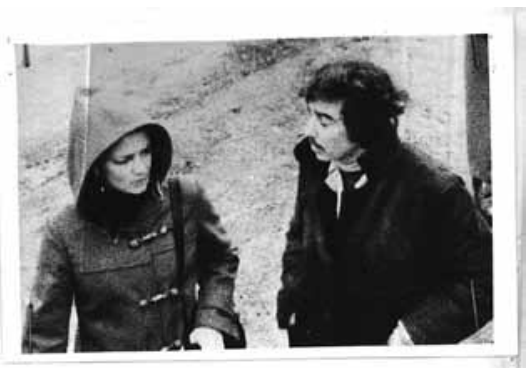

Figura $\mathrm{N}^{\circ} 11$ (arriba izq.). (Ibidem, folio 189). Figura $\mathrm{N}^{\circ} 12$ (arriba der.).(Ibidem, folio 190). Figura $\mathrm{N}^{\circ} 13$ (abajo izq.).(Ibidem, folio 191). Figura $\mathrm{N}^{\circ} 14$ (abajo der.).(Ibidem, folio 191).

\section{Conclusiones}

En la presentación de este artículo, señalamos que el principal objetivo de nuestro estudio fue el de determinar la funcionalidad de las fotografías tomadas por los agentes de la DIPBA en relación con la especificidad de su producción y la conformación de su memoria como comunidad discursiva. En su desarrollo, procuramos caracterizar, desde un enfoque semiótico-discursivo, la fotografía policial de los archivos de inteligencia como género documental, destacando su vinculación con la concepción cientificista de la producción de información sostenida por la comunidad observada, al igual que su importancia en la construcción de un "saber experto" resultante de la actividad de vigilancia del organismo, del que las mismas fotografías son huellas. La consideración de las imágenes analizadas como enunciados visuales, productos de un enunciador cuya identidad se integra a la de la institución y sus funciones, nos permitió enfatizar su dimensión performativa: cada acto fotográfico particular apunta a garantizar el accionar efectivo del Aparato Represivo de Estado sobre los individuos y grupos vigilados. Pudimos entonces introducir nuestra hipótesis de trabajo, relativa a la interdependencia de los enunciados fotográficos, cuyo sentido sólo se establecería a partir del juego enunciativo de las series históricas en el mar- 
co global del archivo; ese sentido se cohesionaría en cierto régimen escópico que contribuiría en la consolidación de la memoria discursiva del grupo, ya que daría lugar a lo que llamamos "una memoria escópica". Ese ángulo de la memoria discursiva de la comunidad pudo rastrearse en los análisis reseñados: en tres coyunturas histórico-políticas distintas, los registros fotográficos incorporados a los informes de inteligencia obedecieron, por una parte, a la voluntad racionalista de ese enunciador "soberano", cuya mirada interviene en la escena para producir datos relevantes y, por otra, al afán empirista de diseccionar el tiempo y el espacio en fragmentos desde una distancia objetivante. Las últimas fotografías analizadas profundizaron esa segunda orientación, acompañando la "profesionalización" demandada a las fuerzas de seguridad desde comienzos de los años setenta, aspecto que se corrobora en las especificaciones técnicas de los informes.

Cabe, finalmente, recalcar que, pese a sus diferencias formales y técnicas, todas las fotografías contempladas han tenido como propósito relevar la presencia y la acción organizada de grupos considerados amenazantes para el orden político o social; de una manera u otra, han registrado un acontecer en un espacio abierto y visible para confinarlo luego al espacio oculto, secreto y cerrado, de los legajos. Desde la perspectiva retórica, la población vigilada es concebida como antiethos, un otro social cuyo avance debe ser combatido o controlado. De esta forma, es posible concluir que, integradas a la actividad discursiva de la comunidad que las produce, clasifica y preserva, las fotografías de los archivos de inteligencia deben ser leídas hoy como la materialización de una mirada destinada, a su vez, a ser mirada, a construir en la inmediatez de su acto una sucesión de visiones que, pese a su desplazamiento, convergen en una misma trama: su función, siempre heterónoma, responde a un hacer antes que a un comprender. Con esta afirmación no hacemos más que reafirmar las condiciones (siempre histórica, política y socialmente situadas) de operatividad de esa comunidad. Su interpretación está siempre sometida a un poder que trasciende su propia naturaleza, que se impone mucho más allá de su iconicidad o su indicialidad, y ese poder, en términos de Foucault, es una positividad: hace mirar para hacer actuar.

\section{Notas}

1. UBACYT Res. Nº932, Código 20020120200039: “El archivo de la Dirección de Inteligencia de la Policía de la Provincia de Buenos Aires (DIPBA). Un caso de comunidad discursiva", 2013-2016; PICT 2015-3712: "La comunidad discursiva del Archivo de la Dirección de Inteligencia de la Policía de la Provincia de Buenos Aires (DIPBA)", 2016-2018; UBACYT Exp. UBA 41268/2016, código 20020150100238BA: "Los archivos de la Dirección General de Informaciones (DGI) de la Provincia de Santa Fe y de la Dirección de Inteligencia de la Policía de la Provincia de Buenos Aires (DIPBA). Un estudio comparativo de dos comunidades discursivas", 2016-2018.

2. La Dirección de Inteligencia de la Policía de la Provincia de Buenos Aires-DIPBA- fue creada en 1956, en el escenario de la proscripción del peronismo luego del golpe de Estado de 1955 y del proceso de redefinición de las fuerzas de seguridad en el contexto de la Guerra Fría, y fue disuelta en 1998, durante el segundo mandato de Carlos S. Menem, por decisión del Ministerio de Seguridad y Justicia de la Provincia de Buenos Aires. El edificio 
donde funcionó la DIPBA y su Archivo fueron cedidos en 2000 a la Comisión Provincial por la Memoria. En 2003, durante la presidencia de Néstor Kirchner, dicho Archivo fue abierto a su consulta pública, despertando principalmente el interés de historiadores, sociólogos y antropólogos sociales y culturales. En el caso de nuestras investigaciones, nuestra atención se ha centrado en la concepción del grupo creador del archivo como comunidad discursiva (Maingueneau, 1987) -es decir, como grupo productor de discursos, de modo que su organización, sus tareas de inteligencia y su propia existencia en cuanto grupo son indisociables de sus prácticas discursivas-, al igual que en la construcción de su memoria discursiva (Courtine, 1981, 1994), entendida como la repetición, reformulación $\mathrm{u}$ olvido, en una nueva coyuntura, de discursos dichos con anterioridad.

3. El legajo o expediente es la unidad documental característica del archivo policial: cohesiona materiales de distintos géneros y procedencias en torno a un mismo asunto.

4. Nos referimos, desde ya, a las imágenes fotográficas registradas por agentes del organismo policial, a diferencia de las obtenidas de otras fuentes (como la prensa) o las incautadas en operativos que, aunque también conforman el material visual del archivo, no se ubican dentro del género. Cabe acotar que, desde 1957, la Central de Inteligencia de la policía provincial disponía de una "mesa técnica" que agrupaba "al personal de dibujantes, fotógrafos e impresores" (documento sobre la Organización de la Central de Inteligencia, carpeta Varios 25, 1957, p. 4). La necesidad de contar con agentes familiarizados con las técnicas de producción y reproducción de imágenes para cumplir eficazmente con las tareas de investigación se hace patente en los programas de estudio de los cursos regulares para personal superior de Inteligencia impartidos por la institución, como puede corroborarse al consultar ciertos documentos de la Mesa Doctrina (v.gr.: Material de estudio, 1981, Caja 2699, leg.14 -Plan y programa de estudio, Curso regular de inteligencia para personal superior, materia Inteligencia IV, Técnicas Investigativas Policiales: "Fotografía” y "Cartografía").

5. Esta caracterización nos permite recuperar también la concepción de "archivo" propia del análisis del discurso: "conjunto de enunciados que, en una sociedad, corresponden a un mismo posicionamiento o que responden a una misma identidad enunciativa, son inseparables de una misma memoria y de las instituciones que les confieren autoridad y legitimidad" (Charaudeau y Maingueneau, 2005, p. 43).

6. En Campos de fuerza. Entre la historia cultural y la crítica intelectual, Jay incluye su célebre ensayo sobre los regímenes escópicos (concebidos, en términos muy amplios, como culturas o subculturas visuales) de la modernidad: un régimen dominante, el perspectivismo cartesiano (implicado con las ideas cartesianas de racionalidad subjetiva; dicho modelo de visualidad funcionaría, de cierta manera, como expresión de la experiencia natural de la visión valorizada por la cosmovisión científica, y conduciría a la reconstrucción de un espacio "geometrizado", esencialmente intelectual) y un segundo régimen, el arte de describir holandés (que suprimiría la referencia narrativa contenidista a favor de la descripción y la denotación visual, lo que supondría un cierto rechazo del rol privilegiado y constitutivo del sujeto monocular y una orientación hacia la observación empirista). No consideramos aquí en el tercer régimen mencionado por Jay (el de la visión barroca), ya que se aleja de las características del material visual que analizamos.

7. En este artículo, por restricciones ligadas a su publicación, nos limitamos a reproducir unas pocas imágenes representativas de cada conjunto. 
8. Los trabajadores de los frigoríficos de Berisso tuvieron un considerable protagonismo en las luchas sindicales y políticas de distintas etapas de la historia argentina. En el periodo que cubre el legajo (entre los gobiernos de Arturo Frondizi y José María Guido) se desarrollaron numerosas huelgas; la más extensa, que respondió a un paro por tiempo indefinido decretado por la federación que reunía a los Sindicatos de la Carne, se inició el 9 de agosto de 1962 y se prolongó por más de cien días.

9. El memorándum o memorando puede definirse como un género discursivo cuyo principal propósito comunicativo es constatar la entrega de información solicitada; la relación entre locutor y alocutario supone un escritor experto y un lector experto (Parodi, 2008).

10. Servicio de Informaciones de la Policía de la Provincia de Buenos Aires, denominación del organismo entre 1961 y 1977.

11. En el contexto del gobierno de facto de J.C. Onganía, tanto este movimiento como las "organizaciones villeras peronistas" eran objeto de vigilancia (y continuarían siéndolo también en la siguiente década, incluso bajo el gobierno justicialista).

12. El 21 de julio de 1973 (ocho días después de la renuncia de Cámpora, bajo la presidencia provisional de Raúl Lastiri, yerno de López Rega), miles de jóvenes pertenecientes a agrupaciones peronistas se concentraron en Vicente López, a pocas cuadras de la General Paz, para encaminarse hacia Gaspar Campos 1065, con el propósito de "romper el cerco" que aislaba a Perón desde su regreso al país el mes anterior. A la cabeza de la movilización estaban los cuatro dirigentes de la Juventud Peronista "Regionales" Juan Carlos Dante Gullo, Miguel Lizaso, Juan Carlos Añón y Roberto Ahumada. Los manifestantes llevaban carteles y banderas de la JP, Montoneros, FAR y FAP. Más de quinientos policías custodiaban la residencia. Los cuatro dirigentes pudieron acercarse a la casa, donde les dijeron que Perón se encontraba en la Quinta de Olivos. Desde allí intentaron comunicarse telefónicamente con el líder y fueron atendidos por López Rega (que ejercía el cargo de Ministro de Bienestar Social), quien les aseguró que Perón los recibiría en la Quinta. Las columnas de jóvenes marcharon entonces hacia allí con esa promesa. Efectivamente, Perón recibió a los dirigentes en un salón de la residencia, pero acompañado por Lastiri y López Rega (quien sospechaba que "debajo de los ponchos" los jóvenes portaban armas largas). Afuera, los participantes de la movilización coreaban consignas tales como "Urgente, urgente, Perón presidente". Mientras la lectura de la reunión fue positiva para los militantes (ya que consideraron que con el encuentro habían sido legitimados por Perón y logrado "romper el cerco" del "Brujo"), los medios oficiales informaron que, por el contrario, López Rega había sido nombrado "delegado personal del Teniente General Perón ante las distintas organizaciones que conforman la Juventud Peronista" (Larraquy, 2018).

13. Como aclaramos en la nota X, "S.I.P.B.A." es una de las siglas empleadas por el organismo a lo largo de su historia.

14. Desde comienzos de la década de los años 70, las fotografías policiales del archivo de la DIPBA cuentan, en su mayoría, con epígrafes que, en ciertos casos, llegan a evaluar la calidad de la imagen. Por ejemplo, en el folio 32 de un legajo dedicado al secuestro y muerte de Pedro Eugenio Aramburu (Mesa Ds, carpeta Varios, legajo $N^{\circ} 137$ ) elaborado entre 1970 y 1971, se indica, bajo las imágenes del interior de una finca inspeccionada en los operativos de rastreo: "La falta de nitidez es debida a que las fotografías fueron tomadas desde las aberturas de las ventanas". 


\section{Referencias bibliográficas:}

Aumont, J. (1992). La imagen. Barcelona: Paidós.

Austin, J. (1981). Cómo hacer cosas con palabras. Barcelona: Paidós.

Barthes, R. (1980). La cámara lúcida. Barcelona: Paidós. . (1986). Lo obvio y lo obtuso. Barcelona: Paidós.

Bettendorff, M. E. (2017). “Entre el espejo y el mapa. Notas sobre producción verbo-visual y regímenes escópicos en los legajos de la DIPBA”. Ponencia presentada en el III Congreso Internacional: Nuevos Horizontes de Iberoamérica, Mendoza, UNCUYO, noviembre de 2017.

Bettendorff, M.E. y Ledesma, M. del V. (2018). “Configuraciones visuales de la vigilancia: las imágenes de los 'villeros' en el archivo de la DIPBA”. Ponencia presentada en el IV SEDiAR (Seminario Internacional de Estudios sobre Discurso y Argumentación), Buenos Aires, Facultad de Filosofía y Letras de la UBA, marzo de 2018.

Charaudeau, P. y D. Maingueneau (dir.) (2005). Diccionario de análisis del discurso. Buenos Aires: Amorrortu Editores.

Chevrier, J.-F. (2009). Proust et la photographie. La resurrection de Venise. Paris: L'Arachnéen.

Courtine, J.J. (1981). "Quelques problèmes théoriques et méthodologiques en analyse du discours, à propos du discours communiste adressé aux chrétiens”. Langages 62, pp. 9-128. . (1994). "Le tissu de la mémoire: quelques perspectives de travail historique dans les sciences du langage”. Langages 114, pp. 5-12.

Didi-Huberman, G. y Charoux, C. (2013). Cuando las imágenes tocan lo real. Madrid: Círculo de Bellas Artes.

Dubois, P. (1986). El acto fotográfico. Barcelona: Paidós.

Foucault, M. (2002). La arqueología del saber. Buenos Aires: Siglo XXI Editores.

Gauthier, G. (1996). Veinte lecciones sobre la imagen y el sentido. Madrid: Cátedra.

Jay, M. (2003). Campos de fuerza. Entre la historia intelectual y la crítica cultural. Buenos Aires: Paidós.

Larraquy, M. (2018). “La teoría del cerco: los deseos imaginarios de Montoneros para negar al Perón real”. Infobae, 9 de julio de 2018.

Maingueneau, D. (1987). Nouvelles tendances en analyse du discours. París: Hachette. . (2009). Análisis de textos de comunicación. Buenos Aires: Nueva Visión.

Montiel Álvarez, T. (2016). "La fotografía policial en el siglo XIX”. ArthyHum, vol. 21, 2016, pp. 148-159.

Parodi, G. (ed.) (2008). Géneros académicos y géneros profesionales: accesos discursivos para saber y hacer. Valparaíso: Editorial Universitaria de Valparaíso.

Perelman, Ch. y Olbrechts-Tyteca, L. (1989). Tratado de la argumentación. La nueva retórica. Madrid: Gredos.

Schaeffer, J-M. (1990). La imagen precaria. Madrid: Cátedra.

Tagg, J. (2005). El peso de la representación. Ensayos sobre fotografías e historias. México: Gustavo Gili.

Vitale, M.A. (2016). "Vigiladores y espías. Imagen de sí, memoria y experticia en el Archivo de la DIPBA", en Vitale, A. (ed.). Vigilar la sociedad. Estudios discursivos sobre inteligencia policial bonaerense. Buenos Aires: Editorial Biblos.

Zunzunegui, S. (1995). Pensar la imagen. Madrid: Cátedra. 


\begin{abstract}
Incorporated into the surveillance device of the State Repressive Apparatus, the character of evidence or evidence of the photographs of the police archives is the product of an institutional construction that converts into knowing what is initially perceived as the imprint of an event. In this article we are dedicated, precisely, to examine the functionality of this genre of images within the Directorate of Intelligence of the Police of the Province of Buenos -DIPBA- in the period 1962-1973. We also propose the concept of "scopic memory" to account for the way of seeing / showing / knowing proper to the institution in relation to its photographic production.
\end{abstract}

Keywords: archive - discursive community - police photography - photographic genres memory - power.

Resumo: Incorporado ao dispositivo de vigilância do Aparelho Repressivo do Estado, o caráter de evidência ou evidência das fotografias dos arquivos policiais é o produto de uma construção institucional que se converte em saber o que é inicialmente percebido como a impressão de um evento. Neste artigo estamos dedicados, precisamente, a examinar a funcionalidade deste gênero de imagens dentro da Diretoria de Inteligência da Polícia da Província de Buenos - DIPBA - no período 1962-1973. Também propomos o conceito de "memória escópica" para explicar o modo de ver / mostrar / conhecer adequado à instituição em relação à sua produção fotográfica.

Palavras chave: arquivo - comunidade discursiva - fotografia policial - gêneros fotográficos - memória . poder

[Las traducciones de los abstracts fueron supervisadas por el autor de cada artículo] 